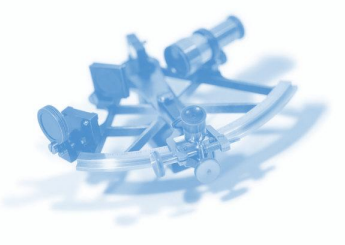

Bruce Sinclair
School of Physics and
Astronomy
University of St Andrews
North Haugh
St Andrews
Scotland
KY16 9SS
b.d.sinclair@st-and.ac.uk

\footnotetext{
We note that many of the aims of the UAS fit with aspects of the honours degree benchmark statement for physics and the Institute of Physics criteria for accredited degrees.
}

\section{The Undergraduate Ambassador Scheme implemented at St Andrews}

\begin{abstract}
The Undergraduate Ambassador Scheme (UAS) is now a well-established project across many UK Universities ${ }^{1,2}$. In this scheme undergraduate students in science, engineering, and mathematics go into local schools to learn from and assist teachers as part of credit-bearing studies for their degree. UAS has a central office that can provide significant help to universities to set up and run such a scheme, though each university is responsible for its own implementation.
\end{abstract}

This article aims to give an overview of the Undergraduate Ambassador Scheme, its implementation in physics at St Andrews in session 2007-8, and the issues and benefits that we have observed in this first year of operation.

Many universities have provided opportunities for their students and local schools by encouraging students to take part in activities in local schools on a voluntary basis. These schemes can prove highly successful. A difference between these schemes and the similar Undergraduate Ambassadors Scheme (UAS) discussed here is that in the UAS the students' work counts towards academic credit in their degree programme. This can make such placements more attractive to students both through the provision of credit and through the recognition by the university that this is a valuable educational experience. The learning experience can be further enhanced by the necessary discussions with university staff and students, and by the reflective work that the students are required to undertake as part of the module. Bringing the placement into a credit bearing module also provides greater incentive for students to be fully committed to the school placements, and may also provide greater incentive for university and school staff to ensure that the students' placements are appropriately supported.

In 2007-8 the University of St Andrews ran the Undergraduate Ambassador Scheme for the first time, rolling out the scheme across its Schools of Physics \& Astronomy, Chemistry, Biology, Mathematics and Statistics, and Geography \& Geoscience. We are told that ours is now the largest implementation of the UAS in Scotland ${ }^{3}$. We acknowledge that other physics departments in the UK have been successfully running this scheme for some time, including the University of Surrey ${ }^{4}$ as one of the first set in 2002-3, with support from the Physical Sciences Centre. There are now some 110 departments in 42 universities running the scheme.

The UAS was set up in 2001 by author and broadcaster Simon Singh. Our University's involvement in the project became more focused after discussions with Simon when he gave a public lecture in St Andrews. The aims of the UAS fitted with our wishes, which were to:

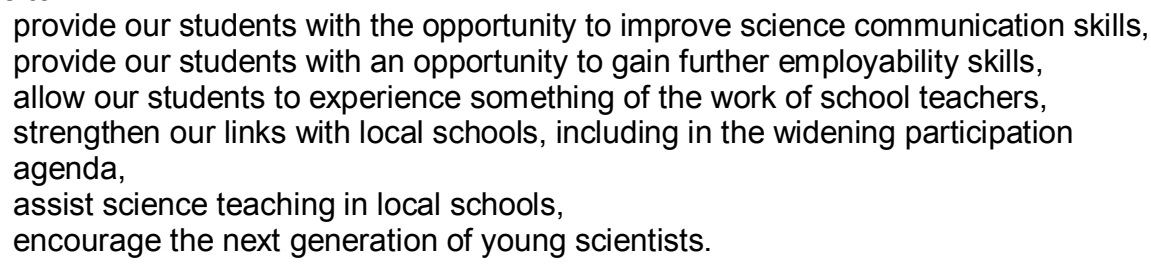

We note that many of the aims of the UAS fit with aspects of the honours degree benchmark statement for physics ${ }^{5}$ and the Institute of Physics criteria for accredited degrees $^{6}$. Our discussions showed that the UAS organisation could provide a great deal of no-cost input in terms of templates for the organisation of such a module, relevant paperwork for use in the module, evaluation reports on the scheme, and even some financial support. 
Dr Alyson Tobin of the School of Biology took the lead in the organisation of the new module, in collaboration with academic staff in each of the participating departments. In due course the University's committees gave approval to a new interdisciplinary module ID4001 Communicating and Teaching Science. In St Andrews this module runs in the first semester and is worth 15 credits of the standard student load of 120 credits a year. The module handbook, which is available online $^{7}$, was based on the excellent material on the UAS website $^{1}$

Academic staff and Schools-liaison staff worked with local schools to find placements for the students. Late in the academic session we invited applications for a place on the module from students in their final year (final plus penultimate year for MPhys students) Interviews were held to select the students to participate in the module, which included for physics students a conceptual query on rocket thrust from a "pretend" 14 year old. The selection procedure is unusual in our system, but then so is this module. The schools and the University needed to be sure that those going into schools are committed to the activity and bringing relevant expertise to the placement. It is usual for our students to be able to change their choice of module for a short time at the start of the academic session, but this cannot be the case for this module, given the external commitment. While the selection committee was aware of the academic qualifications of the applicants, this was not the primary factor.

Over the summer, successful applicants went through the formal process to ensure that they had not been determined as being unsuitable for working with children, and students and teachers were linked together. In the first year of operation 32 students were placed in 11 Schools in Fife and the former Tayside. Seven of these were physics students.

Students attended a workshop in orientation week to help prepare them for the school placements. This included an external speaker from Her Majesty's Inspectorate of Schools, who has been involved in many of the recent curriculum developments. We are fortunate to have a number of university staff members who are former school teachers, and they also contributed to the induction session, along with a student who had taken part in voluntary work in schools. As well as hearing about current work in schools, our students were actively engaged in various "what if?" scenarios.

The students were required to liaise with their link school teachers to determine what times of the week would best suit their own timetable and that of their school. They then attended the school for the equivalent of a morning a week for the duration of our semester. Email seemed to make this arrangement work more easily than might have been the case in the past. The students organised their own visits to the schools, with the University providing travel expenses for those with a longer journey. Our students reported in most cases being warmly welcomed into their schools, with their anxiousness being eased by the care that the teachers took in integrating them into the school communities.

The intention was that the first visits would be primarily observing the teacher at work with various classes, and then as the semester progressed the students would take a more active role with, for example, helping with practical classes and in one-to-one support with pupil questions. In some cases a student borrowed equipment from our department to illustrate the work being done in school, for example by taking in an endoscope to a lesson on total internal reflection and light guides. The goal was to build on these experiences with a "special project" towards the end of the semester, where the student would take the lead on part or all of a lesson, albeit under the direct supervision of the host teacher. Special projects in physics included bringing one group to the University to undertake relevant teaching-lab experiments, developing a statistics lesson based on sampling from packets of sweets, and developing and presenting a "fun" educational quiz on electronics.

The students were required to reflect on their experience after each school visit and compiled a log book that identified the successful aspects of the visit and aspects that needed improvement. They also worked closely with the teacher in preparing for the next visit through revision and writing any necessary teaching plans. The main "teaching" of the students was done through discussion between the student and teacher, but support was also provided in the University through small group tutorial sessions with a subject tutor. A great deal of experiential learning was also taking place, both in the professional skills and in a deeper understanding of the physics topics involved. The academic staff in all subjects noted how quickly most students' confidence grew through the teaching and communication experiences in the module.

Assessment of the students' achievements was done in four ways:

$25 \%$ on the school teacher's view of the student's work $25 \%$ on the content of the student's log book

$25 \%$ on the student's end-of-module reflective analysis and report

$25 \%$ on an oral presentation on a chosen aspect of the student's work.

We evaluated the module via anonymous questionnaires with the students, input from teachers, and our own observations. 
Three of the physics students offered comments that they were willing to have published:

Student A: - "This module has given me invaluable experience in science communication. It not only gave me an insight into teaching various age groups but also how to go about communicating ideas to them in a relevant way. As I was mostly teaching just one class I was able to build up a relationship with the pupils in said class and I hope that I may have inspired some of them to carry on studying physics at higher levels and made them realise that physics isn't boring but can also be extremely useful and fun. I think that this is an excellent scheme both for students like myself, for the experience it gives us in teaching, communication and interpersonal skills; and for the pupils in the schools, as it gave them someone to relate to that wasn't a teacher and was nearer their age so that they could find out what university was like."

Student B: - "I thought overall the module was very well put together, containing lots of aspects which will be useful as career skills. It offered enough classroom time to get a feel for whether teaching would interest me full time, without getting too involved at the school, which was a good thing due to time pressures with a subject such as physics. The module ensured the development of transferable skills with much of the assessment based around self analysis of a range of skills from communication to planning and time management.

In some respects I felt the self analysis expected of us was slightly excessive, however, it did highlight the large range of skills one can benefit from by taking ID4001. I liked being able to work directly with the teacher in planning the level of involvement that I could afford and be comfortable with. In all I thought the module was enjoyable, interesting and rewarding, and would recommend it to anyone, especially those who might consider teaching at some stage in their career."

Student C: - "The ID4001 module offered a valuable insight into the education system that I believe is hidden from the general public. For me, as a science undergraduate, I relished the opportunity to play my part in rectifying the shortage of applicants to higher education in the subject.

The managerial skills that I have developed and attribute to participating in the module I believe will be important for my future career. The experience of organising and augmenting a lesson, in addition to dealing with all the unexpected issues that arise from a class of high school students as they happen, will be priceless. I have learnt the importance of clear and thorough communication, and have gained an understanding of the skill that is required in the use of language style and visual aids to avoid misunderstanding in an audience. Accordingly, I have developed even more respect for those in the difficult profession that is teaching.

Overall, I hope that the students and teachers I worked with gained as much from my participation in the classroom as I did. In addition, through my enthusiasm and by utilising the facilities that St Andrews School of Physics and Astronomy has at its disposal, I hope that students experienced a modern and exciting side of physics that would otherwise have been beyond the constraints of the classroom."
We felt that the module ran remarkably well, which is testament to the support provided by the UAS office, and the input from students and school teachers. For the coming session we are reducing the emphasis on the daily log books, and some of the summative assessment procedures will be moved from the end of the module to part way through. The teachers' assessment stays at $25 \%$, and we are introducing a "proposal" document for the special project at $10 \%$. The oral presentation will be on the Special Project and be worth $30 \%$, and the balance will be on the written report on the placement, which will use information from the reflective log sheets.

At the request of the teachers we will try to get students into the schools a little earlier, as in some cases last session students had only just got into the schools before the October break. The tutorials that I run will be more structured, and I will endeavour to increase the amount of feedback through formative assessment.

One senior teacher commented "The scheme seems to have been well received here as well; I think it does well because it has a clear focus and end result as opposed to an ad hoc arrangement."

We now have other departments within the University seeking to join the scheme, and the total number of students being placed in the coming session has risen to 42 , which says positive things about the way that this initiative has been received by schools, staff and students.

\section{References}

1. Undergraduate Ambassadors Scheme website: $<$ www.uas.ac.uk> accessed 17 July 2008.

2. How to get a taste for teaching, Physics World, May 2005.

3. Undergraduate Ambassadors Scheme Newsletter November 2007, URL:

<www.uas.ac.uk/news_story.php?id=262> accessed 17 July 2008.

4. Dick Bacon and Ravi Kapur, Undergraduate Ambassadors Scheme, LTSN Physical Sciences News 5 (March 2004), 4.

5. Subject benchmark statement for physics, astronomy, and astrophysics 2008, The Quality Assurance Agency for Higher Education, $<w w w . q a a . a c . u k / a c a d e m i c i n f r a s t r u c t u r e / b e n c h m a r k /$ statements/Physics08.pdf> accessed 17 July 2008.

6. Physics Degree, Graduate Skills Base and the Core of Physics, $<w w w$.iop.org/activity/policy/Degree_Accreditation/ file_26578.pdf $>$ accessed 17 July 2008 .

7. ID4001 website at the University of St Andrews, <biology.st-andrews.ac.uk/pageset.aspx?psr=338>. 